\title{
TAX REVISIONS OF 2004 AND PRO SPORTS TEAM OWNERSHIP
}

\author{
N. EDWARD COULSON and RODNEY FORT*
}

\begin{abstract}
Tax law revisions of 2004 altered the "roster depreciation allowance" enjoyed by pro sports team owners. Supporters claimed this would practically eliminate costly legal oversight by the IRS and, ultimately, increase owner tax bills. Government officials and leagues remained silent on team value impacts but outside analysts argued they would rise by 5\%. We model this policy change and investigate it empirically. Supporters in Congress were absolutely correct that owner tax payments should increase but outside analysts underestimated team value increases by half. No wonder Major League Baseball and the National Football League favored the revision.

(JEL D21, G38, H25, L83)
\end{abstract}

\section{INTRODUCTION}

In 1946, Major League Baseball (MLB) entrepreneur Bill Veeck convinced the IRS that the roster of players on his newly acquired Cleveland Indians was a depreciable asset (Veeck, 1962). Okner's (1974) assessment of this "roster depreciation allowance" (RDA) first appeared nearly $30 \mathrm{yr}$ later. The point of his work, and subsequent work after nearly another 20 yr by Quirk and Fort (1992), was to elucidate the illogical foundations and ongoing consequences of the RDA. Despite these flaws, the RDA has endured and its recent treatment under the tax revisions of 2004, effective 2005, is the subject of this paper.

Under previous tax laws established in 1976, from 1977 to 2004, sports team owners were allowed to treat $50 \%$ of the team purchase price as an asset depreciable over no more than $5 \mathrm{yr}$, what we refer to as the "50/5 Rule." The 2004 revision set the RDA at $100 \%$ of the purchase price depreciable over no more than $15 \mathrm{yr}$, what we will refer to as the "100/15 Rule." All interested parties agreed that administrative enforcement costs would be driven to zero because,

*We thank Michael Wark for helpful research assistance, and Michael Coulson, Virginia Bullard, and anonymous referees for helpful comments.

Coulson: Department of Economics, 508 Kern Graduate Building, Pennsylvania State University, University Park, PA 16802. Phone 814-863-0625,

E-mail fyj@psu.edu

Fort: Program in Sport Management, University of Michigan, 1402 Washington Heights, Rm. 3150, Ann Arbor, MI 48109-2013. Phone 734-647-8989,

E-mail rodfort@umich.edu under the lavish percentage and depreciation period of the 100/15 Rule, no real legal challenges would be raised. Controversy over this revision did arise over the impacts on both team owner tax payments and team values.

Congressional supporters argued that owners would pay more taxes. A report by the Congressional Joint Committee on Taxation said the revisions would increase owner tax bills $\$ 381$ million over 10 years. Industry experts disagreed, stating flatly that the revisions would generally lower tax payments by owners (Wilson, 2004 , p. 2). To round out the controversy completely, a lobbyist-spokesman for MLB stated that tax payments would remain unchanged (Wilson, 2004, p. 3).

Turning to franchise values, members of Congress were silent but the same industry experts claimed the RDA revisions would raise the capital values of sports franchises. Lehman Brothers publicly stated that the revisions would add about $5 \%$ to sports team values across all leagues. Raymond James \& Associates more vaguely agreed that team values would "increase" (Wilson, 2004, p. 3).

League officials, their lobbyists, and team owners were much less committal. They agreed there would be some advantages but chose instead to downplay the tax advantages and focus on the issue of owners suffering true net operating losses (Rovell, 2004, p. 1). Both Jeff Smulyan, previous owner of MLB's Seattle Mariners, and David Samson, President of MLB's Florida Marlins, voiced that the benefits of depreciation are small consolation for owners facing true operating losses. Ted Leonsis, owner of the NHL's Washington Capitals, said, "I look 
forward to the day where (write-offs are) an issue for me."

While its public statements downplayed the value of the RDA, MLB actively lobbied for the revisions and the National Football League (NFL) also publicly supported them. The National Basketball Association (NBA) and National Hockey League (NHL) remained neutral. Ostensibly, the reason for this lobbying was more about saving on legal fees than on raising franchise values, William H. Schweitzer, a managing partner of the Washington law firm that promoted the revisions for MLB, saying they would have a slightly positive impact, varying from club to club. The revisions would eliminate IRS disputes without significantly changing taxes. Indeed, he offered that MLB had not specifically evaluated how the revisions would affect franchise values (Wilson, 2004, p. 3).

We present a model of the RDA capable of sorting out these conflicting opinions. The model shows the impact of the RDA on team value and the impact of changes in the RDA on team values and taxes paid by owners. We hold all other values of team ownership constant and allow owners to either hold the team or sell it after the RDA depreciation period expires. Thus, we are able to (1) show the value of the RDA in terms of team operating profits, (2) provide comparative statics results for parameters of the RDA, (3) explore the role of the "other values" held constant, and (4) apply our findings to the controversy just detailed.

Our results suggest that supporters in Congress were qualitatively correct (although we cannot comment quantitatively on their $\$ 381$ million over $10 \mathrm{yr}$ ); taxes paid by owners should have increased. In addition, while MLB team values should have increased, outside analysts appear to have underestimated franchise value impacts by half. Because our model shows that the value of the RDA increased under the 2004 revisions even though taxes increased, it is small wonder that MLB and the NFL lobbied in favor of the 2004 revision.

Interestingly, if it weren't for all of the other values owners enjoy beyond operations and tax benefits under the RDA, the revisions of 2004 would have led to a fall in team values, instead. Many of the "other values" of team ownership could be reduced by other types of policy intervention. If teams were more closely defined through policy intervention as standalone assets, our model predicts that owners would be more likely to follow the strategy of selling their team at the expiration of the RDA depreciation period. Under that strategy, our model predicts that team values would have fallen with the 2004 revisions.

The paper proceeds as follows. In Section II we describe the RDA in more detail. Section III contains our model of the impact of the RDA on team value, including sensitivity of team values to the changes in the RDA and other parameters determining team values. Section IV employs actual data on the parameters in our model to show relative team values and tax payments, under each of the ownership approaches, for the case at hand. Conclusions round out the paper.

\section{THE ROSTER DEPRECIATION ALLOWANCE}

The purchase of a professional sports franchise consists mainly of the rights to intangible assets. Some intangible assets derive from league membership (territorial rights, revenue shares from attendance and television, and shares of future expansion fees) while others derive from their relationship with state and local hosts (revenues from tickets, parking, and concessions). Finally, there are "other values" like related business opportunities, accounting costs that are actually profit-taking, revenueshifting tax advantages from joint ownership, and, the point of this paper, tax advantages through the RDA. Fort (2006) discusses all of these other ownership values in detail, including those from the RDA, and estimates that they might be upwards of $18 \%$ of actual recent sale values.

Historically, the assignment of value to particular assets evolved arbitrarily. Bill Veeck describes how he wrested the RDA from the IRS after he bought the Cleveland Indians in 1946 (Veeck, 1962; Quirk and Fort, 1992). Essentially, Veeck assigned the bulk of the firm's value $(90 \%)$ to the intangible player roster asset and devised a depreciation schedule ( $5 \mathrm{yr}$ ) to reduce his taxable obligation on the team. A possible parallel is the depreciation of livestock that is purchased for work, breeding, or dairy purposes but not kept in an inventory account. Apparently, these types of livestock "wear out" in their relative productive roles and the IRS allows them to be treated as depreciable assets for tax purposes.

Okner (1974) and Quirk and Fort (1992) made the difference between livestock and athletes quite clear. First, while some players may be in the declining end of their careers, still other 
players are appreciating in value; it is not at all clear that "the roster" itself depreciates. Second, it is relatively easy to conceive a value in player contracts, but team owners do not own players as breeders own livestock. Third, the depreciation allowance surely involves double counting because the salaries and player development costs that create the asset are already treated as expenses at market-determined values. Far from recognizing these inconsistencies, the IRS even changed its treatment of contracts to allow single player contracts to become depreciable and subject to capital gains if held long enough (Ambrose, 1985, p. 173).

There were IRS challenges of subsequent large RDA claims by other owners. One of the most famous involved the current MLB Commissioner, Bud Selig. A group led by Selig bought the bankrupt Seattle Pilots in April of 1970 for $\$ 10.8$ million and moved them to Milwaukee. The IRS challenged Selig's claim that $94 \%$ of the purchase price could be attributed to the player roster and demanded a large tax adjustment. Selig sued and won the case (Selig v. U.S., 565 F. Supp. 524). Eventually, tax reform legislation in 1976 set the 50/5 Rule and revisions in 2004 set the 100/15 Rule. The point of what follows is to compare the impact on team values and owner taxes of the move from the former to the latter.

\section{THE MODEL}

We assume the team is structured as a pass through, for example a subchapter $\mathrm{S}$ corporation or limited partnership, a reasonable assumption for professional clubs (Vrooman, 1997) so that all tax savings occur at the individual income tax rate. In most cases, the size of the depreciation is easily enough to eliminate any taxes that would have been paid on the team's net operating revenues, and actually to shelter income from other endeavors besides team ownership. We choose to focus on this tax shelter value of the pass through to the individual tax forms of team owners.

While the tax-saving value of the RDA is one of the "other values" of ownership mentioned in the last section, there is no reason for changes in the RDA to have any cross-effect on any of the rest of the other values. All the other values also are held constant in order to focus on the qualitative nature of the impacts of the RDA on the value of team ownership. However, in the end, we return to the impact of possible changes in the other values in order to speculate on actual observed owner decisions to hold their team after the RDA depreciation period expires.

Because all other values are held constant, the model is based on the tried-and-true assumption that the fundamental value of the firm is equal to the discounted flow of operating profits and, in the case of the RDA, tax savings on team operations and pass-through shelter of taxable income from other endeavors besides team ownership. In this setting, we further assume net operating revenue, non-roster depreciation, amortization, and remaining parameters of the model remain constant over time. We will also assume that net revenue after subtracting non-roster depreciation and amortization is positive, but less than the value of roster depreciation. This assures that the pass-through value of the RDA is positive. Finally, we'll use simple straight-line depreciation, as this is required for intangible assets (Quirk and Fort, 1992).

Our approach is to define the model first for the absence of RDA. This is the appropriate benchmark case under the assumption that the intangibles to which the depreciation expensing is applied do not, in fact, depreciate (which seems like a useful approximation). Under this assumption the absence of an RDA prevents the distortion of capital toward professional sports franchises and is in that sense efficient. We then introduce the RDA to the model under two alternative ownership strategies. We do not model the choice (although we examine it empirically, later), but owners can hold the team into perpetuity after the RDA depreciation period expires (henceforth, the "hold strategy") or sell the team after the RDA depreciation period expires (henceforth, the "sell strategy"). Our notation is as follows:

$$
\begin{aligned}
V_{\mathrm{j}} & =\text { present value of team ownership; } \\
j & =1 \text { for no RDA; } \\
j & =2 \text { for the hold strategy; } \\
j & =3 \text { for the sell strategy; } \\
Y & =\text { annual net cash flow from operations; } \\
i & =\text { interest rate; } \\
T & =\text { highest marginal personal income tax } \\
& \text { rate; } \\
a & =\text { length of the RDA period; } \\
b= & \text { percent of the team value assigned to } \\
& \text { roster value; } \\
c= & \text { capital gains tax rate. }
\end{aligned}
$$

Without any RDA in the constant cash flow case without any taxation, $V_{1}=\sum_{t=1}^{\infty} \frac{Y}{(1+i)^{t}}=\frac{Y}{i}$. 
Our base case, adding in taxation but without the RDA, is just:

$$
V_{1}=\frac{(1-T) Y}{i} .
$$

Introducing the RDA, the present value calculation depends on what happens to the equity once the RDA depreciation period expires. Under the hold strategy, $V_{2}$ decomposes to two parts, the years under the RDA and the period after the RDA depreciation period expires for the team. For the RDA years, the net cash flow from operations after taxes is $(1-T) Y$. In addition, the RDA saves the owner taxes on the value assigned to the player roster divided by the number of years allowed. Under straight-line depreciation, this is just $\left(\frac{b V_{2}}{a}\right) T$. This is pure income tax avoidance because the true cost of the depreciation of the asset is zero. After the RDA depreciation period runs out, the owner becomes liable for the taxes from the cash flow as part of their personal income. Combining elements and discounting, after a bit of arithmetic, we find:

$$
\begin{aligned}
V_{2}= & \sum_{t=1}^{a} \frac{(1-T) Y+\left(\frac{b V_{2}}{a}\right) T}{(1+i)^{t}} \\
& +\sum_{t=a+1}^{\infty} \frac{(1-T) Y}{(1+i)^{t}}=\frac{1}{1-K T\left(\frac{b}{a}\right)} V_{1} \\
& =z_{2} V_{1} .
\end{aligned}
$$

In expression (2),

$$
K(a, i)=\sum_{t=1}^{a} \frac{1}{(1+i)^{t}}=\left(\frac{1}{i}\right)\left[1-\frac{1}{(1+i)^{a}}\right]
$$

is the present value of one dollar of depreciation expense over the RDA period.

First, note that $z_{2}$ is the value of the RDA for the hold strategy as a multiple of team value absent the RDA; this coefficient is the relative value of the RDA in this case. Second, note that $z_{2}>1$ unambiguously, because the denominator in (2) is a positive fraction; $K<a$ and $0<b, T<1$. Unambiguously, then, the direct value $V_{2}>V_{1}$. All else constant, if the owner holds the team into perpetuity after the RDA depreciation period ends, the value of ownership is larger than it would be without the RDA.
The impact on tax payments is also unambiguous under the hold strategy. From (1), tax payments are equal to $R_{1}=\frac{T Y}{i}$. Rearranging (2), $V_{2}=\frac{z_{2} Y}{i}-\frac{z_{2} T Y}{i}$, and tax payments in this case are $R_{2}=\frac{z_{2} T Y}{i}$. If $z_{2}>1$, then $R_{2}>R_{1}$. Thus, our first insight about the RDA is that, even though team value increases unambiguously under the hold strategy, taxes paid also will increase. Clearly, the value of the tax shelter is bought with a higher tax bill.

Under the sell strategy, the owner enjoys the value of cash flow plus the value of the RDA up to the expiration of the depreciation period and then the owner must pay capital gains tax on the sale. The value of cash flow and tax shelter over the duration of the RDA is captured as in $V_{2}$. Turning to capital gains, the new owner will be able to start the RDA all over again upon purchase and would be willing to pay whatever the previous owner was willing to pay, that is $V_{3}$ (effectively, the value of the RDA becomes a perpetuity). The IRS would view the capital gain as $V_{3}-(1-b) V_{3}=b V_{3}$. This is the sale price minus the value of the remaining assets of the club because on the books the player contracts have zero value. The present value of the profit from the sale is thus $\frac{V_{3}-c\left(b V_{3}\right)}{(1+i)^{a}}=\frac{(1-b c) V_{3}}{(1+i)^{a}}$ (discounting occurs from the time that the sale takes place at the expiration of the RDA depreciation period). Combining all of these elements and invoking the definition of $\mathrm{K}$ in (3), a bit of algebra yields:

$$
\begin{aligned}
V_{3} & =\sum_{t=1}^{a} \frac{(1-T) Y+\left(\frac{b V_{3}}{a}\right) T}{(1+i)^{t}}+\frac{1-b c V_{3}}{(1+i)^{a}} \\
& =\frac{1}{1-b\left[\frac{T}{a i}+c\left(1-\frac{1}{K i}\right)\right]} V_{1}=z_{3} V_{1} .
\end{aligned}
$$

We note the following. First, $z_{3}$ is the RDA multiple under the sell strategy relative to no RDA. Second, a large enough difference between $c$ and $T$ reveals that $V_{3}$ can be poorly defined in (4) because the denominator may be less than or equal to zero. Let $D=$ $\left[\frac{T}{a i}+c\left(1-\frac{1}{K i}\right)\right]$, the bracketed term in the denominator of (4). The first element of $D$ is related to the value of the RDA during the depreciation period and is greater than zero. The second element of $D$ is related to the payment of capital gains tax after the depreciation 
period is ended. This term is negative because $1-\frac{1}{K i}<0$. Thus, a positive denominator in (4) is required for $z_{3}>0$ :

$$
z_{3}>0 \Leftrightarrow c>\frac{T K(1+i)^{a}}{a}-\frac{(1+i)^{a}-1}{b} .
$$

If the capital gains tax rate is smaller than required in (5), so that $z_{3}<0$, we hasten to point out that the value of the firm is not negative. Instead, $V_{3}$ in (4) is simply not well defined in this case. For $z_{3}<0$, the value of the passthrough tax shelter is only limited by the amount of the owner's income from sources other than team operations (Quirk and Fort, 1992, p. 119). The possibility of a negative $z_{3}$ dictates special care in comparisons between the results in (1), (2), and (4).

Third, even if (5) holds so that $z_{3}>0$, the sell strategy only increases the value of the team relative to no RDA as follows:

$$
z_{3}>1 \Leftrightarrow c<\frac{T K(1+i)^{a}}{a} .
$$

It can be shown by the definition of $K$ in (3) and the expansion of the resulting polynomial that $\frac{K(1+i)^{a}}{a}>1$. Thus $c<T$ is a sufficient condition for (6). Even the condition $c>T$ will be enough for the buy and sell strategy to be value-enhancing. Absence of such a condition (i.e., for $c$ sufficiently greater than $T$ ) will be the case when $V_{2}>V_{1}>V_{3}$ and the best of all options open to the owner is to claim the RDA and employ the hold strategy.

The fourth and final observation is that even if $z_{3}>1$, its relationship to $z_{2}$ is as follows:

$$
z_{3}>z_{2} \Leftrightarrow c<\frac{T K}{a} .
$$

Satisfaction of (7) again requires $c<T$ (sufficiently small, because $K<a$ ) and even smaller than that required by (6). Thus, rather than the unambiguous results for the hold strategy, the impacts of the RDA under the sell strategy remain ambiguous. For precisely the same reason, the impact of the RDA on owner tax bills under the sell strategy remains ambiguous. From (4), $V_{3}=\frac{z_{3} Y}{i}-\frac{z_{3} T Y}{i}$ so that taxes paid are $R_{3}=\frac{z_{3} T Y}{i}$. If the magnitude of $z_{3}$ is ambiguous, then our theory alone cannot determine whether or not $R_{3}>R_{1}$ or $R_{3}>R_{2}$.

Thus, our second observation about the RDA is that our theory alone cannot dictate if team values or owner tax bills are higher under the sell strategy relative to either no RDA or the
TABLE 1

Comparative Statics Summary

\begin{tabular}{lccccccc}
\hline & & \multicolumn{5}{c}{ Parameters } \\
\cline { 2 - 7 } & Value & $\boldsymbol{Y}$ & $\boldsymbol{i}$ & $\boldsymbol{T}$ & $\boldsymbol{a}$ & $\boldsymbol{b}$ & $\boldsymbol{c}$ \\
\hline$(1)$ & $z_{2}$ & 0 & - & + & - & + & 0 \\
$(2)$ & $R_{2}$ & + & - & + & - & + & 0 \\
$(3)$ & $z_{3}$ & 0 & $\left(^{*}\right)$ & + & $\left(^{*}\right)$ & $\left({ }^{* *}\right)$ & - \\
$(4)$ & $R_{3}$ & + & $\left(^{*}\right)$ & + & $\left(^{*}\right)$ & $\left(^{* *}\right)$ & - \\
\hline
\end{tabular}

Notes: Only outcomes for $z_{3}>0$ are calculated.

*Negative for sufficiently small values of $c$.

**Positive for sufficiently small values of $\mathrm{c}$.

hold strategy. We turn to data on the parameters of our model to shed light on these relationships in the next section. But before we turn to the data on our model parameters, while knowing values are important, so is knowledge of the impacts of changes and we turn to comparative statics for insights.

Lacking verifiable cash flow data, we restrict our attention to comparative statics with respect to $z_{2}$ and $z_{3}$, that is, comparisons of team values relative to $V_{1}$. In addition, we also show comparative statics for tax payments in each case, $R_{2}$ and $R_{3}$. Details of the derivations are contained in an appendix available from the authors and the results are displayed in Table 1.

For the hold strategy, comparative statics results are from straightforward differentiation. Of particular interest (Table 1, row 1), the relative value of the RDA falls with an increase in the depreciation period under the RDA $\left(\frac{\partial z_{2}}{\partial a}<0\right)$ and increases with an increase in the percentage of the purchase attributed to the RDA $\left(\frac{\partial z_{2}}{\partial b}>0\right)$. In addition, the relative value of the hold strategy increases with increases in the personal income tax $\left(\frac{\partial z_{2}}{\partial T}>0\right)$. The impacts are qualitatively the same for these variables for tax payments as well (Table 1, row 2). These comparative statics results yield a third insight into the workings of the RDA. All else constant, an increase in the personal income tax rate raises the relative value of the hold strategy and owner tax bills but simultaneous increases in $a$ and $b$ (as occurred in the 2004 revisions) have opposite effects on both of these.

Things are decidedly less clear cut for the sell strategy as indicated by the discussion immediately following expression (4), above. In the first place, the comparative statics results are only meaningful for $z_{3}>0$, that is when (5) holds and this relative tax shelter value is finite. Suppose this is the case and, as before, let $D=\left[\frac{T}{a i}+c\left(1-\frac{1}{K i}\right)\right]$ be 
the bracket term in the denominator of (4). The impact of a change in the percentage of purchase price applied under the RDA has $\operatorname{sign}\left(\frac{\partial z_{3}}{\partial b}\right)=$ $\operatorname{sign}(D)$. For the remaining parameters, sign $\left(\frac{\partial z_{3}}{\partial j}\right)=\operatorname{sign}\left(\frac{\partial D}{\partial j}\right)$. Similar ambiguity governs the comparative statics for tax bills under the sell strategy.

As with the hold strategy, the relative value of the sell strategy, $V_{3}$, and owner's tax bills itself increase with the personal income tax rate (Table 1, rows 3 and 4, respectively). In addition, both of these fall with the capital gains tax rate. The rest of the comparative statics results depend on the level of the capital gains tax rate relative to the personal income tax rate. For example, the qualitative change in team value and owner tax bills for the sell strategy with respect to the length of the RDA period and the percentage of purchase price attributed under the RDA are the same as for the hold strategy only for sufficiently small values of the capital gains rate. As noted above, passing judgment on these requires attention to the actual value of the parameters at various time periods of interest and we turn to that task directly in the next section.

A summary of our model findings is as follows. First, even though team value increases unambiguously with the RDA under the hold strategy (relative to no RDA), taxes paid also will increase. Second, our theory alone cannot dictate if team values or owner tax bills are higher under the sell strategy or not. Data on the parameters of our model are required to settle the issue. Third, all else constant, an increase in the personal income tax rate raises the relative value of the hold strategy and owner tax bills but increases in the parameters of the RDA, $a$ and $b$, have conflicting effects on both of these: an increase in $a$ lowers them, while an increase in $b$ raises them. Under the sell strategy these results hold only for sufficiently small values of the capital gains rate. Settling this last issue also requires attention to the data on the parameters of interest.

\section{PARAMETER DATA AND THE IMPACT OF THE 2004 TAX REVISIONS}

To settle the ambiguities detailed in the last section and gain insight into the controversy outlined in the introduction, we turn to data on the interest rate, personal income tax rate, and capital gains tax rate. Given the income levels of
TABLE 2

Model Parameters for Various RDA Episodes

\begin{tabular}{lcccc}
\hline Parameter & $\begin{array}{c}\text { 50/5 Rule } \\
(\mathbf{1 9 7 7 )}\end{array}$ & $\mathbf{1 9 9 0}$ & $\mathbf{2 0 0 3}$ & $\begin{array}{c}\mathbf{1 0 0 / 1 5} \text { Rule } \\
\mathbf{( 2 0 0 5 )}\end{array}$ \\
\hline$i$ & $6.13 \%$ & $6.44 \%$ & $0.91 \%$ & $3.98 \%$ \\
$T$ & $70 \%$ & $28 \%$ & $35 \%$ & $35 \%$ \\
$a$ & $5 \mathrm{yr}$ & $5 \mathrm{yr}$ & $5 \mathrm{yr}$ & $15 \mathrm{yr}$ \\
$b$ & $50 \%$ & $50 \%$ & $50 \%$ & $100 \%$ \\
$c$ & $39.9 \%$ & $28 \%$ & $15 \%$ & $15 \%$ \\
\hline
\end{tabular}

Sources: $i=13$-wk T-Bill yield index from the Global Financial Data (2008); $a$ and $b$ are known from Quirk and Fort (1992), Rovell (2004), and Wilson (2004); $c$ and $T$ are from the Citizens for Tax Justice (2008); and $\mathrm{K}$ is from the text, expression (3).

Notes: All values are actual values except that i and c are averaged over the 1971-1976 period (the income tax rate was constant during the period).

owners, we focus only on the rates paid by top income earners. The capital gains rate has been less than the income tax rate except for a brief period when they were equal, 1988-1990. The data (and sources) are shown for representative years in Table 2-the effective date of the 50/5 (1977), halfway between the 50/5 Rule imposition and the 100/15 Rule imposition (1990, also representative of that short period when personal income and capital gains tax rates were equal), the year just prior to the creation of the 100/15 Rule (2003), and the effective date of the 100/15 Rule (2005).

Lacking verifiable cash flow data, we must examine relative values of the hold and sell strategies and the results are in Table 3 for each of the years in Table 2. Table 3, row 1, shows the behavior of $z_{2}$. Compared to the codification of the 50/5 Rule effective in 1977, the relative value of the hold strategy was $20.4 \%$ lower in $1990,14.8 \%$ lower in 2003, and returned to within $95 \%$ of its 1977 value for the codification of the 100/15 Rule effective in 2005 .

Our comparative statics results flesh out a story of how parameter changes contributed to the results just described for the hold strategy.

\section{TABLE 3}

Team Values Relative to $V_{1}$, Various RDA Episodes

\begin{tabular}{|c|c|c|c|c|c|}
\hline & Approach & $\begin{array}{l}\text { 50/5 Rule } \\
\text { (1977) }\end{array}$ & 1990 & 2003 & $\begin{array}{l}\text { 100/15 Rule } \\
\text { (2005) }\end{array}$ \\
\hline (1) & "Hold" & 1.42 & 1.13 & 1.21 & 1.35 \\
\hline (2) & "Sell" & 2.30 & 1.06 & -0.81 & 1.66 \\
\hline (3) & {$[(2)-(1)] /(1)$} & $63 \%$ & $7 \%$ & $\infty$ & $23 \%$ \\
\hline
\end{tabular}

Notes: Calculated from expressions (1) through (4) in the text using the parameters in Table 2. 
First, remember that the parameters of the RDA itself remained unchanged for 1977, 1990, and 2003. For 1990, our comparative statics results suggest that all changes that occurred $(i, T$, and $c$ ) should decrease the relative value of the hold strategy and, indeed, it fell. For 2003, both the continued decline in the interest rate and the increase in the personal income tax rate raised the relative value of the hold strategy. Finally, the impact of the RDA parameter changes under the 100/15 Rule are in opposite directions (raising the percentage of the purchase price should raise the relative value of the hold strategy but increasing the length of the depreciation period should have an offsetting effect) and an increase in the interest rate should decrease the relative value of the hold strategy. For the imposition of the 100/15 Rule, the increase in the percentage of the purchase price must have dominated since the relative value of the hold strategy increased.

The relative value of the sell strategy $\left(z_{3}\right.$, Table 3, row 2) exhibits one example quite important relative to our theoretical derivations in the last section: $z_{3}<0$ means the RDA's value was essentially bounded only by the amount of non-team owner income for 2003! The relative values of the sell strategy were more down-to-earth for the 50/5 Rule effective in 1977 and the 100/15 Rule effective in 2005 .

While we can only observe that the relative value of the sell strategy essentially was large enough to erase personal income tax obligations for owners in 2003, our comparative statics results paint compelling pictures for 1990 and 2005. Because of the ambiguities for this strategy detailed in the previous section, we stress that, given the data in Table 2, the relative value of the sell strategy should increase with the percentage of the purchase price applied under the RDA, decrease in the interest rate (except for 2003 where it increases in the interest rate), and decrease in the length of the depreciation period under the RDA. For 1990, the effects of the increased interest rate and decline in the personal income tax rate offset the effects of the decline in the capital gains tax rate since the relative value of the sell strategy declined. To return to a negative value in 2003, the effect of the interest rate had to overcome the effects of an increase in the personal income tax rate and a decline in the capital gains tax rate. The last decline in the relative value of the sell strategy cannot be attributed solely to the imposition of the 100/15 Rule. One element of the newest rule, increasing the length of the depreciation period under the RDA, should reduce the relative value of the sell strategy, but the other element, increasing the percentage of the purchase price applied under the RDA, should increase the value. Further, increased interest rates would also act to lower the relative value of the sell strategy.

As our final examination of the results shown in Table 3, we compare the relative values of the hold and sell strategies ( $z_{2}$ and $z_{3}$, respectively). This comparison is essential in order to discuss and interpret actual hold behavior by owners. It is immediately clear (Table 3, row 3 ) that the relative value of the sell strategy was larger than the relative value of the hold strategy for all of the tabled years. For example, at the effective date of the 50/5 Rule (1977), the advantage for the sell strategy was $63 \%$.

The smallest advantage exists in 1990, but the results of our model in the last section help explain this outcome. While the increasing interest rate may well have been an important kicker and the relative values of both the hold and sell strategies fell, it is also true that the personal income tax rate and the capital gains tax rate both fell and became equal to each other. Quirk and Fort (1992) offered the intuitive explanation that any added resale value attached to the sell strategy when $c>T$ would disappear when $c=T$ so that the value of the RDA should be equal under either the hold or sell strategy, that is $z_{2}=z_{3}$. We refine the Quirk and Fort intuition by noting from (7) that $z_{3}=z_{2} \Leftrightarrow c=$ $\frac{T K}{a}$, where $K<a$. Thus, $c=T$ is not sufficient for $z_{2}=z_{3}$; instead, $c$ must be slightly less and, in this period where $c=T$, the hold strategy is actually slightly better $(1.13>1.06)$.

For 2003, the relative advantage of the sell strategy is only limited (theoretically) by the amount of non-team other income on owners' 1040 forms. While the advantage of the sell strategy should have fallen under the 100/15 Rule, it still remained $23 \%$ greater than the relative value of the hold strategy.

It is time to put our theoretical and empirical observations into the context of team owner hold choices - we cannot address the controversy unless we know whether owners will actually hold or sell their teams at the expiration of whatever RDA depreciation period. Because we are not interested in modeling and explaining that choice, we instead just observe which choices are made from the data on team sales in MLB.

In Table 4, we compare a variety of statistics on holding periods and the like for all 
TABLE 4

Team Holding Statistics, MLB, 1977-2004

\begin{tabular}{lcc}
\hline & $\begin{array}{c}\text { Last } \\
\text { Owner }\end{array}$ & $\begin{array}{c}\text { New } \\
\text { Owner }\end{array}$ \\
\hline New Expansion Teams & & 4 \\
w/o Expansion Team Transactions & & \\
Total purchases & & 26 \\
Omitted & 0 & 3 \\
Held < = 5 yr & 3 & 1 \\
Held 6-10 yr & 8 & 11 \\
Held > 10 yr & 15 & 11 \\
Average years held & 20.5 & 12.3 \\
Sales w/decreased hold & & 15 \\
\% Increase in sales & & $7.0 \%$ \\
\% Decline in average hold & & $-39.9 \%$ \\
\% w/Decline in hold & & $65.2 \%$ \\
Expansion Team Transactions & & \\
Total purchases & & 15 \\
Omitted & 0 & 5 \\
Held < = 5 yr & 3 & 3 \\
Held 6-10 yr & 4 & 3 \\
Held > 10 yr & 8 & 4 \\
Average years held & 11.9 & 9.1 \\
Sales w/decreased hold & & 6 \\
\% Increase in sales & & $275.0 \%$ \\
\% Decline in average hold & & $-23.5 \%$ \\
$\%$ w/Decline in hold & & $60.0 \%$ \\
\hline & & \\
\hline
\end{tabular}

Sources: Compiled from data in appendices of Quirk and Fort (1992), data at Fort (2008), and the most recent MLB team valuations in Ozanian and Badenhausen (2008).

Notes: There were 27 purchases excluding expansion franchises for 1946-1976, 10 new expansion teams, and 4 expansion team purchases (after the original entry franchise price). Percentage increase in the number of sales is on a per year basis since the earlier period is three years longer. Twenty-three teams had not been resold as of 2004 so that hold durations for new owners were not evident ( 2 for 1946-1976 and 21 for 1977-2004). If the team had been held longer than $5 \mathrm{yr}$ as of 2004, their hold is stated as of 2004 and they are included in subsequent calculations. If the team had been held $5 \mathrm{yr}$ or less as of 2004, they are in the "Omitted" category in the table and omitted from subsequent calculations where relevant.

MLB owners purchasing teams during the reign of the 50/5 Rule, 1977-2004, and their predecessor owners. There are insufficient observations for any statements about the 100/15 Rule. In addition, it is useful to separate expansion team transactions from others since the number of expansion teams is different in each period. Finally, teams that were purchased during the 50/5 Rule period but not sold again to date require special attention (see the notes to Table 4).

Two things are interesting to note. First, compared to the preceding $30 \mathrm{yr}$ when the RDA was evolving and excluding expansion team transactions, the number of sales increased
$7 \%$, the holding period declined $39.9 \%$, and the vast majority of teams $(65.2 \%)$ were held for a shorter number of years under the 50/5 Rule. Second, the vast majority of teams also were held longer than the duration of the RDA; 22 out of 26 longer than $5 \mathrm{yr}(84.6 \%)$. Other than selling like hotcakes relative to the preceding period (by a factor of 2.75), the story is the same for expansion teams as it is for the rest under the 50/5 Rule. Thus, it is safe to say that owners during this period clearly were not choosing the sell strategy. Indeed only four owners (including three expansion team owners) during this period actually did so. If all remaining purchases yet to be resold did so within $5 \mathrm{yr}$ of purchase, there would be 8 more but even 15 would be well below a majority of the 49 total sales.

If teams really were as we have modeled them, owners clearly should be adopting the sell strategy. However, this just brings us back to our assumption that all "other values" of ownership were constant. Fort (2006) makes it clear that other values loom large and the results in Table 4 suggest that owners overwhelmingly reject the sell strategy in order to hold on to these other values. This is reasonable because it is highly likely that other values rose during the reign of the 50/5 Rule.

First, Fort (2006) shows that other values (for our purposes, unfortunately, including the value of the RDA) can represent upwards of $18 \%$ of recent sale prices. He also documents $5.3 \%$ and $9.5 \%$ real rates of growth in team sale prices for average holding periods over the 1970 s and 1980s, respectively (relative to $2.5 \%-3 \%$ for the economy at large). Second, Humphreys and Mondello (2008) show that a quality-adjusted index of major league sport franchise prices practically exploded beginning in the late 1970s. But an examination of "typical revenues in MLB" (Fort, 2008) over this period shows an annual real rate of growth around $4.3 \%$ for 1974-1980. The rest of the explosion in team prices seem reasonably to have been fueled by increases in other values.

And that brings us finally to our chance to inform the controversy detailed in the introduction. Extrapolating the hold strategy into the reign of the new 100/15 Rule, team values and owner tax payments should rise about $11.6 \%$ (1.21-1.35 in Table 3, row 1). So, Congressional supporters were precisely correct; taxes would increase under the 100/15 Rule. Our model does not allow us to cast judgment on the $\$ 381$ million increase over $10 \mathrm{yr}$ since we 
do not know of any starting values for tax payments. However, even though they were right qualitatively, outside observers were decidedly low in their quantitative estimate of impacts on franchise values; our $11.6 \%$ calculation is fully 2.3 times their $5 \%$ claim.

It is small wonder that major leagues were at worst neutral (NBA and NHL) and at best highly supportive (MLB and NFL) of the 2004 revisions. Their costs and benefits are easily isolated looking at what happened immediately to the first crop of team sales in 2005. The 2005 team sales were $\$ 600$ million for the NFL's Minnesota Vikings, \$375 million for the NBA's Cleveland Cavaliers, \$220 million and \$180 million for MLB's Oakland Athletics and Milwaukee Brewers (respectively), and \$75 million for the NHL's Anaheim Mighty Ducks.

On the cost side, we know of no other data on tax payments than those offered by the Congressional Joint Committee on Taxation cited in the introduction. Their estimate of an additional \$381 million in tax revenues over $10 \mathrm{yr}$ yields $381 / 10=\$ 38.1$ million per year ignoring discounting. That would be an additional $\$ 10.0$ million for the 32-team NFL, or about $\$ 312,500$ per owner annually. For the remaining three 30-team leagues, including MLB, each league total is $\$ 9.5$ million, or about $\$ 316,700$ per owner annually. These additional average taxes are at least indicative of the cost to the first crop of owners that sold their teams in 2005.

On the benefit side, the predicted $11.6 \%$ increase would be immediately capitalized into observed sale prices. The $11.6 \%$ increases are thus $\$ 69.6$ million for the Vikings owner, $\$ 43.5$ million for the Cavaliers owner, \$25.5 million for the Athletics owner, \$20.9 million for the Brewers owner, and $\$ 8.7$ million for the Mighty Ducks owner. Across all four pro leagues, benefits clearly swamp costs. Indeed, we are left wondering why either the NBA or the NHL remained neutral.

It is tempting to label the downplayed claims by owners and their lobbyist in the introduction as disingenuous. For example, $\mathrm{Mr}$ Leonsis dismisses write-offs like those under the RDA as insignificant to him. He purchased his NHL Washington Capitals in 1999 for a reported $\$ 85$ million (Ozanian, Badenhausen, and Settimi, 2007), or $\$ 99.5$ million 2005 dollars. Even if there were no other increase in the team price except an inflation adjustment to 2005, our calculation says that the increase would represent $0.116 \times 99.4$
$=\$ 11.5$ million. This increase would have been large enough to recoup $11.5 \%$ of the $\$ 100$ million in losses attributed to Leonsis' ownership to 2004 (Rovell, 2004, p. 1).

Put another way, by the Joint Committee report of additional taxes, the average tax payment for each NHL owner, as stated above, would have increased about $\$ 316,700$ from 2004 to 2005 . If this is the $11.6 \%$ increase suggested by our results, the average tax bill for NHL operations in 2004 would have been 316,700/.116= $\$ 2.7$ million. Using 33\% for the top tax bracket puts average taxable net revenues on operations of 2.7/0.33 $=\$ 8.2$ million in 2004. Because $\mathrm{Mr}$ Leonsis apparently is far below the average, his worst-case franchise value gain of $\$ 11.5$ million is $40 \%$ greater than the average taxable NHL net revenue.

It is perhaps fairer to try to determine what else pro team owners and their advocates might have had in mind. For example, the value of our model parameters beyond the outset of the 100/15 Rule is subject to uncertainty. Expectations about interest rates and personal income tax rates (but probably not capital gains tax rates since the hold strategy seems to be the order of the day) may have been behind their downplayed claims. But even this argument is slightly diversionary. Statements based on expectations about these other parameters are beside the point from the perspective of the RDA! Those other parameters have nothing to do with a statement about changes in either the percentage of purchase price attributed under the RDA or the length of its depreciation period.

As a last general observation in this day and age where preferential economic treatment of wealthy owners is highly criticized, we note the following. Suppose government policies toward the other values enjoyed by owners were so tight that owners viewed their teams as stand-alone assets. In this case, the value of team ownership would be as we have it modeled and it seems safe to say that the sell strategy would dominate. But if so, the imposition of the 100/15 Rule would have had dramatically different impacts! From Table 3, row 2, the value of the sell strategy would have fallen under the 100/15 Rule.

On the other hand, the value of the sell strategy would still be $23 \%$ higher than the hold strategy, a fact that generates the following final insight. If they are obtained politically by investment in the welfare of politicians that keep these "other values" flowing, then these other values must be at least as much as the 
$23 \%$ potential gain in Table 4 . The opportunity cost to owners of their enjoyed "other values" is the $23 \%$ increase they could have employing the sell strategy for teams that are more like stand-alone assets.

\section{CONCLUSIONS}

The "RDA" allows pro sports team owners to count a percentage of their team purchase price as a depreciable asset over a specific number of years. The RDA impacts the value of sports team ownership by reducing team tax obligations and providing pass-through tax shelter of an owner's income from other endeavors besides team ownership. Tax law revisions of 2004 increased the amount of team purchase price attributed to the RDA from $50 \%$ to $100 \%$ and the allowed depreciation period from 5 to $15 \mathrm{yr}$. Supporters claimed this would practically eliminate costly legal oversight by the IRS and increase owner tax bills. Government officials remained silent on team value impacts but outside analysts argued they would rise and both MLB and the NFL lobbied in favor of the revisions.

Modeling the RDA impact on the value of team operations, we investigate this policy change. Holding all "other values" of ownership constant, we formalize the value of operating a sports team and enjoying the financial benefits of the RDA for both a strategy where the team is held after the RDA depreciation period runs out and a strategy where the team is sold after the RDA depreciation period runs out. Applying actual data on the parameters of our model suggests that supporters in Congress were absolutely correct. Tax payments by owners should have increased. Those arguing that tax payments would decrease may have expectations about future cash flow, personal income tax rates, and/or interest rates that are different than the levels at the time of the revision in 2004. However, none of those pertain to the revisions of the RDA, itself, under the 2004 revisions. Further, outside analysts missed the mark substantially. Increases in team values attributable to the RDA were likely to be just over twice their claims. Even though MLB remained silent on the impact on team values, our findings help explain support for the revisions by MLB and the NFL.

On a closing note, many of the "other values" of team ownership could be reduced by other types of policy intervention. If teams were more closely defined through the policy process as stand-alone assets under the law, owners would be more likely to follow the strategy of selling their team at the expiration of the RDA depreciation period. Interestingly, if such were the case, the value of teams would reasonably have been predicted to fall, instead, under the 2004 revisions. But since returns under the sell policy are $23 \%$ higher, and owners could reasonably bargain their "other values" politically for this higher return on operations, then "other values" must be worth more than the gain under the sell strategy. Policy toward sports team owners is surely a many-splendored thing.

\section{REFERENCES}

Ambrose, J. F. "The Impact of Tax Policy on Sports," in Government and Sport, edited by A. Johnson and J. Frey. Totowa, NJ: Rowman and Allenheld, 1985, $171-86$.

Citizens for Tax Justice. "Top Federal Income Tax Rates on Regular Income and Capital Gains since 1916." 2008. Accessed July 7, 2008. http://www.ctj.org/pdf/re gcg.pdf.

Fort, R. "The Value of Major League Baseball Ownership." International Journal of Sport Finance, 1, 2006, 9-20.

Fort, R. Rodney Fort's Sports Business Data Pages. 2008. Accessed July 7, 2008. www.rodneyfort.com/Sports Data/BizFrame.htm.

Global Financial Data. "CBOE 13-Week U.S. Treasury Bill Yield Index.” 2008. Accessed July 7, 2008. http:// www.globalfinancialdata.com/index.php3 ?action=Sear ch\&seriestype $=$ Treasury_Bill_Yields \& country=USA\& startime $=1000 \&$ endtime $=3000$.

Humphreys, B. R., and Mondello, M. "Determinants of Franchise Values in North American Professional Sports Leagues: Evidence from a Hedonic Price Model." International Journal of Sport Finance, 3, 2008, 98-105.

Okner, B. A. "Taxation and Sports Enterprises," in Government and the Sports Business, edited by R. G. Noll. Washington, D.C.: Brookings Institution, 1974, 159-84.

Ozanian, M. K., K. Badenhausen, and C. Settimi. "The Business of Hockey." Forbes 2007. Accessed July 7, 2008. http://www.forbes.com/2007/11/08/nhl-teamvalues-biz-07nhl_cx_mo_kb_1108nhl_land.html.

Ozanian, M. K., and K. Badenhausen. "The Business of Baseball." Forbes 2008. Accessed July 7, 2008. http:// www.forbes.com/2008/04/16/baseball-team-valuesbiz-sports-baseball08-cx_mo_kb_0416baseballintro. html.

Quirk, J., and R. D. Fort. Pay Dirt: The Business of Professional Team Sports. Princeton, NJ: Princeton University Press, 1992.

Rovell, D. "New Owners' Tax Break Losing Value." ESPN. com, April 15, 2004. Accessed July 7, 2008. http:// sports.espn.go.com/espn/sportsbusiness/news/story?id $=1782953$.

Veeck, B. (with E. Linn). The Hustler's Handbook. New York, NY: G.P. Putnam's Sons, 1962.

Vrooman, J. "A Unified Theory of Capital and Labor Markets in Major League Baseball." Southern Economic Journal, 63, 1997, 594-619

Wilson, D. "Bill Would Raise Franchise Value of Sports Teams." New York Times, August 2, 2004. Accessed July 7, 2008. http://www.nytimes.com/2004/08/02/ sports/02tax.final.html. 